\title{
A Discussion on the Railway Bill's Property of the Document of Title
}

\author{
GaoRuiqi $^{1, a}$ \\ ${ }^{1}$ Beijing Jiaotong University, graduate class 1502, international trade major, Beijing 100044 China \\ aruiqi0307@foxmail.com
}

Keywords: International railway direct transport; railway bill; document of title; ocean bills of lading; transportation costs

\begin{abstract}
In recent years, with the constant reinforcement of trade contacts between countries, as the best mode of land freight transportation, railway transportation is increasingly concerned. With the rapid development of Eurasia railway direct transport, the railway transportation of the region is gradually featured with remote distance, long time and large capacity. And it is similar to sea transportation. From the perspective of transport document, railway bills and ocean bills of lading have the essential difference-whether there is the property for document of title. Under the similar background, whether the property of railway bill and what is the influence on trade after changes will be the primary problems in the study.
\end{abstract}

In 2016, in the reply of the Letter on Soliciting International Railway Direct TCM Convention and Appendix Draft by the Comprehensive Division of State Railway Administration from the General Office, it emphasizes that "in order to greatly develop the role of international railway freight transportation on promoting international trade development, it suggests studying and learning from the relevant practice of ocean transportation field in the working process of International Railway Direct TCM Convention, discussing and designing the international railway transport with property for document of title, reducing the possible commercial risks of international railway transport, and improving the positivity of international trade to use international railway transport between relevant countries in Eurasia.” The requirement makes people pay more attention to the relationship between railway bill and document of title.

\section{Feature Overview of Ocean Bills of Lading}

The ocean transportation is the leading transport mode in international logistics. It accounts for $2 / 3$ in total freight of international trade and $90 \%$ of Chinese import and export freight. Both of them apply marine transport. The bills applied on marine transport refer to ocean bills of lading. These are cargo receipts issued by carriers(ship-owning companies) after receiving cargos. They are also the certificates of transportation contracts signed between shippers and carriers. In addition, original bills of lading also stand for the ownership of cargos and also the vouchers of real right property. Bills are proper for marine transport. The ocean bills of lading are featured with cargo receipts, transportation contract certificates and document of title to cargos.

The ocean bills of lading have the following role in the trade process. (1) The issuers of ocean bills of lading are responsible for the overall process of lift cargos. (2) They are equipped with the document of title. The party holding bills enjoys right to control and control power for cargos or can be used as the negotiable securities for transfer and mortgage. (3) They can be used as the settlement of exchange for letter of credit. According to the relevant requirements in the letter of credit, the combined transport bills of lading and other trade documents to be filled should be audited through the banks. Exporters can timely receive payment for goods and accelerate capital turnover. 


\section{The Development Situation of Eurasia Railway Direct Transport}

Direct transport means that railway consigns cargos in vehicles. For providing convenience for shippers or consignees, it can be free from reloading operation stations or connection stations of different property ownership to transact the transport procedures and it just needs a transportation bill to finish freight transport of cargos. In current stages, there is the international railway cooperative association between "Organization for Cooperation of Railways"(for short "OCR”) and "International Railway Transport"(for short "OTIF") in Eurasia and there are different suitable transport rules in the respective range, including Agreement of International Railway Through Freight Traffic(for short AIRTFT) and International Convention Concerning the Carriage of Goods by Rail(for short ICCCGR). The Eurasia direct transport needs the railways of two railway transportation organizations and needs transportation rules and transportation specifications adapting to each country.

Two international railway transport organizations propose the Eurasia direct transport problems. However, there are some different laws and transport standards in transport rules of two organizations, involved in transport rules, transport conditions, procedure methods, freight fare, customs procedures, and financial settlement in railways. Under the original situation, when AIRTFT participates in national railways to send cargos to ICCCGR participating in national railways, it must transact the transfer procedures as the last(the first) AIRTFT participating in the national railways and transact the transport bills of another transport system, showing the great workload. In this way, it extends the cargo delivery time, but also increases the transportation expenses. In order to solve the above-mentioned problems, OSJD and OTIF established the combined working team to commonly compile the uniform transport receipts_-AIRTFT" and "ICCCGR". In July 2006, it was firstly trialed in Ukraine, but the utilization of the uniform receipts fails to completely cover countries in two railway organizations. As a result, receipts of ICCCGR, receipts of AIRTFT and coexistence of ICCCGR/AIRTFT.

In addition, the uniform receipts have no property for document of title as the certificate of transportation contracts. Under the circumstance of settling relevant expenses of railways, carriers and consignees can conduct the normal delivery, so that the rights and interests of exporters can't be completely safeguard. Meanwhile, in settlement for letter of credit, because it is not the document of title, banks can't share risks by detaining receipts or dealing with the receipts under the circumstance of breaking a contract by exporters, thus settlement for letter of credit is seldom used. This is not good for increasing the trade positivity of exporters, so as to obstruct trade development.

\section{The Transportation Costs under the Time-space Dimension}

As previously mentioned, the unsuccessful receipt circulation will extend the transport time of cargos and bring the extra transportation costs. In the trade process, both trade parties should firstly consider the costs and earnings. The railway transport is a dynamic process. The cargo operation and receipt circulation have a close relationship in time and space from the beginning to the end. As a result, the author will introduce the time-space economic theory to discuss the influences of the property for document of time on the transportation costs in international trade.

The commodity transportation in international trade inevitably is completed in the space. As a result, transportation must overcome the space distance. Until now, there is no transportation mode and transportation tool neglecting commodity transport. In this way, transport inevitably costs considerable time, while overcoming spatial distance. For this problem, the Professor Rong Chaohe(2011) defined distance from time significance, showed that "time distance, in a narrow sense, refers to time required by moving the spatial distance between human and cargos in economic activities and also indicated that "time distance not only includes freight time, but also contains the connection and transformation time required by overcoming spatial barriers(called as the connection time)". "The entire transportation process should be considered as the chain of the transportation displacement." The proposal of the displacement chain enables us to comprehend the transportation cost problems from the new perspective of the time-space dimension. 
To overcome the spatial distance needs to pay the price, such as freight payment, and so on. Similarly, to overcome time distance also needs to pay the price, including running time and connection and transformation time required by overcoming the spatial barriers. The connection time of freight includes loading and unloading, reloading and storage. In essence, transportation is completed in time space. The transport costs refer to the sum to pay the price, in order to overcome the time-space distance. Under the time-space dimension, we think that the generalized transport costs don't mean the simple expense expenditures, but it tends to the summing costs. Under the circumstance, it can't be measured by quantity. Next, the author will combine with mathematic expression to state.

\section{The Influences of Railway Bill' Circulation on Transportation Costs}

In physical truth, in the complete railway transportation process, the displacement of cargos from the starting point to the destination is completed, generating the spatial distance. All time cost on the way results in the time distance. The formula is simplified as follows: $\mathrm{C}_{\text {sum }}=\mathrm{C}_{\text {spatial distance }}+\mathrm{C}$ time distance.

$\mathrm{L}$ stands for the complete distance. $\mathrm{f}$ refers to the transportation expense per unit. c stands for the resource cost occupied and consumed by unit distance, attaining: $C$ spatial distance $=\mathrm{L}(\mathrm{f}+\mathrm{c})$. Time distance costs also include the storage costs and commodity impairment generated in the operation and connection process, let $\mathrm{a}$ and $\mathrm{b}$ stand for the storage costs in unit time and commodity impairment rate, obtaining: $\mathrm{C}_{\text {time distance }}=\left(\mathrm{T}_{\text {operation }}+\mathrm{T}_{\text {connection }}\right) *(\mathrm{a}+\mathrm{b})$. Then, the speed $\mathrm{v}$ is added. Meanwhile, considering some accidents and human error factors affecting the transportation costs, the function $(\mathrm{t})$ is introduced as the function of time $\mathrm{t}$. as $\mathrm{t}=0$, the transportation doesn't start, $\mathrm{P}(\mathrm{t})=0$.

After integration, it can obtain $\mathrm{C}_{\text {sum }}=[\mathrm{v}(\mathrm{f}+\mathrm{c})+\mathrm{a}+\mathrm{b}] \mathrm{T}$ operation $+\mathrm{T}$ connection $*(\mathrm{a}+\mathrm{b})+\mathrm{P}(\mathrm{t})$

Considering that there are different links in the transportation process, the formula can be summarized as:

$\mathrm{C}_{\text {sum }}=[\mathrm{v}(\mathrm{f}+\mathrm{c})+\mathrm{a}+\mathrm{b}]_{\text {operation } \mathrm{i}}+(\mathrm{a}+\mathrm{b})_{\text {connection } \mathrm{i}}+\mathrm{P}(\mathrm{t})$

Assuming that the transportation route is the same, the transportation speed is also the same. Next, the author will discuss the influences of the receipt system on transportation costs through two situations.

\section{The receipts have no property for document of title.}

When receipts have no property for document of title, there is the same connection time as operating with cargos. When the receipts can't be circulated smoothly for problems, the dead time of cargos will be extended, resulting in the extra dad time, called as $\mathrm{D}_{\text {dead }}$. When receipts have problems, the spatial distance of cargos is different, but storage costs and impairment costs in time distance are constantly formed, namely:

$\mathrm{D}_{\text {dead }}=(\mathrm{a}+\mathrm{b}) \mathrm{T}_{\text {receipt treatment }}$

As a result, the longer receipt treatment time is, the higher receipts' dead costs will be.

Under the circumstance, the sum of transportation costs is:

$\mathrm{C}_{\text {sum }}=[\mathrm{v}(\mathrm{f}+\mathrm{c})+\mathrm{a}+\mathrm{b}]_{\text {operation } \mathrm{i}}+(\mathrm{a}+\mathrm{b})\left(\right.$ connection $_{\mathrm{i}}+$ receipt treatment $\left.\mathrm{i}\right)+\mathrm{P}(\mathrm{t})$

The size of transportation costs is proportional to the receipt treatment time. The longer receipts' dead time is the higher transportation costs will. Moreover, the overall trade costs also will be higher.

\section{Receipts' Property for Document of Title}

When the receipts have the property for document of title, the independent circulation mode will be applied. In this way, the operation costs of receipts will be generated, namely $\mathrm{D}$ operation. Due to the separation from cargos, it avoids from the dead time with cargos and avoids from the dead costs caused by unsmooth receipt treatment. The transportation costs are shown as follows:

$\mathrm{C}_{\text {operation }}=[\mathrm{v}(\mathrm{f}+\mathrm{c})+\mathrm{a}+\mathrm{b}]_{\text {operation } \mathrm{i}}+(\mathrm{a}+\mathrm{b})_{\text {connection } \mathrm{i}}+\mathrm{P}(\mathrm{t})+\mathrm{D}_{\text {operation }}$

When receipts arrive in buyers' hands before cargos, it can accelerate capital recycling and transportation, reduce possible commercial risks, and create certain economic value, because of circulation, financing and settlement. We call it as W. W is out of the range of transportation costs. At present, we can't conduct the specific quantization on the value, but the existence can reduce the 
trade costs to some extent. As a result, in order to display more intuitively, we can classify the variable $\mathrm{W}$ into the transportation cost formula, namely:

$$
\mathrm{C}_{\text {sum }}=[\mathrm{v}(\mathrm{f}+\mathrm{c})+\mathrm{a}+\mathrm{b}]_{\text {operation }} \mathrm{i}+(\mathrm{a}+\mathrm{b})_{\text {connection } \mathrm{i}}+\mathrm{P}(\mathrm{t})+\mathrm{D} \text { operation- } \mathrm{W}
$$

To sum up, the above-mentioned two simulations affect the trade costs through $(a+b)$ receipt treatment $i$ and $\mathrm{D}$ operation - W. Based on the railway transportation environment with remote distance and large freight, relative to the cargo storage costs and impairment costs, the author thinks that the operation costs of the receipts are just a small part. Moreover, with the influences of extra economic value on total trade costs, the consignment nodes with the property for document of title have the positive influences on reducing the trade costs of railway transportation.

\section{Reflection and Summary}

According to the concept of displacement chain, the paper constructs the transportation cost expression under the time-space dimension. The qualitative analysis shows the influences of receipt circulation on transportation costs and trade costs. When the receipts circulate with cargos, it will result in cargo retention for too long disposal time and bring the extra time-lag costs. When railway bill have the property for document of title, it can circulate independently. This is good for speeding up the buyers' capital circulation speed and creating certain economic value. As a result, to endow property for document of title will be good for reducing trade costs. The consignment note circulation in current stages has already had lots of problems, resulting in bad influences on traders' rights and interests and successful degree of national trade. It is necessary to formulate the receipt circulation mode under the trade requirements, so as to reduce possible commercial risk of international railway transportation and enhance the positivity of relevant countries in Eurasia to use the international railway transport to do international trade.

\section{References}

[1] Rong Chaohe, Transport-Logistics Time Value and Role in Economic Time-space Analysis[1], Economic Study, 2011(8): 133-146

[2] Rong Chaohe, Fundamental Role of Time-Space Analysis in Economic Study[J], Journal of Beijing Jiaotong University(Social Science), 2014(4): 1-11

[3] Sun Shanshan, Brief Discussion on the Feasibility of International Intermodal Transport as the Real Right Receipts[J], Business Conditions, 2013(28): 149-149

[4] Hu Zhengliang and Cao Chong, the Reflection on the Document of Title[J], Annual of China Maritime Law, 1996(6): 53-78

[5] Wang Wushun, the Discussion of Railway Combined Transport Document under L/C[J], External Foreign Trade Practice, 2002(5): 14-16 